\title{
Taphonomic impact of ultrasonic treatment on foraminifera from a deep-sea carbonate ooze
}

\author{
Rik Van Bael ${ }^{1 *}$, Arne Deprez ${ }^{1}$, Peter Stassen ${ }^{1}$, André Bornemann² \& Robert P. Speijer1 \\ ${ }^{1}$ Department of Earth \& Environmental Sciences, KU Leuven, Celestijnenlaan 200E, B3001 Heverlee, Belgium \\ ${ }^{2}$ Bundesanstalt für Geowissenschaften und Rohstoffe, Stilleweg 2, 30655 Hannover, Germany \\ *Correspondence: vanbael.rik@gmail.com
}

Received 23 December 2015; accepted 25 January 2016

\begin{abstract}
The selection and identification of foraminifera in chalky, partially silicified sediments can be problematic, as was experienced with upper Danian (Paleocene) samples from Newfoundland Ridge (IODP Expedition 342 Site 1407). Ultrasound treatment can potentially improve the liberation and identification of foraminifera by removing fine-grained material from the tests, leading to reduced processing time. However, this process is potentially destructive and can alter the composition of foraminiferal assemblages by reducing fragile taxa from the record, similar to the effects of dissolution (Nguyen et al. 2011).

Results from earlier studies on the impact of ultrasonic treatment on preservation are scarce and contradictory. Hodgkinson (1991) considered the process damaging, especially for fragile ornamentations and not as successful as anticipated as impurities remained while external damage increased. Kennedy \& Coe (2014), however, used a brief ultrasound (15-30 s) procedure during freeze-thaw processing, and reported no visible damage. Lirer (2000) applied a prolonged ultrasound method (1-2 h) after treatment with acetic acid and reported no damage either. Therefore, an experiment was performed to assess the positive and negative effects of the duration of ultrasonic treatment on the quality of the microfossil residues, consisting of c. $99 \%$ planktic foraminifera.
\end{abstract}

\footnotetext{
Material and methods

The study material from IODP Site 1407 (Hole A, Core 22, 208.10 to 211.85 CCSF; Norris et al. 2014) is part of ongoing Palaeogene climate research. The studied sediments consist of $50-65 \% \mathrm{CaCO}_{3}$, with the remaining $50-35 \%$ being mostly opal-CT, clinoptilolite (zeolite) and clays. The samples initially underwent three cycles of wet sieving and oven drying, yet the microfossil content remained partially covered by chalky sediment. Therefore, a well-preserved sample, in which most microfossils were recognizable, and a poorly preserved sample, containing minor signs of lithification and generally poorly recognizable microfossils, were selected from the study material to assess the influence of initial preservation on the process. The well-preserved sample was split into 16 equal parts of $\pm 40 \mathrm{mg}$. The poorly preserved sample, containing small lithified fragments, was split into 8 equal parts of $\pm 40 \mathrm{mg}$. The sample splits were put in plastic cups filled with demineralized water and subjected to different durations of submersion in a Branson 2210 ultrasound bath at a frequency of $40 \mathrm{kHz}$. Afterwards the splits were dry-sieved, weighed and ultimately wet-sieved and weighed again.

The cleanness of the tests is assessed by observations on 200 randomly selected foraminifera. A specimen is considered clean if the test is free of sediment and sutures are clearly visible. Fragmentation is measured by the percentage of tests containing holes. To assess the taphonomic effect on different size fractions
}

and for comparison with older literature, both the $>63 \mu \mathrm{m}$ and $>125 \mu \mathrm{m}$ fraction are evaluated. Removal of fine-grained material is calculated by the loss of mass $>63 \mu \mathrm{m}$ during each treatment step.

\section{Results and discussion}

For both samples, the remaining mass decreases with increasing ultrasound duration (Fig. 1a). This is explained by removal of finegrained material and by fragmentation of tests. Very little mass was lost after dry sieving and, although this increases with ultrasound duration, microfossils remained covered with sediment and cleanness improved only marginally. Subsequent wet sieving yielded significant cleanness improvements. After $18 \mathrm{~min}$ (1080 s) ultrasound exposure, the well-preserved sample had lost $>20 \%$ of its mass.

The foraminifera showed initial fragmentation values between 15 and $30 \%$ for both samples (Fig. 1b). Fragmentation percentages increase significantly with increasing ultrasound exposure time, confirming the damaging effect on foraminiferal preservation (a doubling occurred over $18 \mathrm{~min}$ ). The percentage of damaged foraminifera in the $>125 \mu \mathrm{m}$ fraction increases at the same rate as that of the $>63 \mu \mathrm{m}$ fraction. Yet, the $>125 \mu \mathrm{m}$ fraction of the wellpreserved sample contains a higher percentage of damaged foraminifera at the start of the experiment. This difference could explain the reported high fragmentation ratio for ultrasound treatment in older literature (e.g. Hodgkinson 1991) in which sieving was often done at $125 \mu \mathrm{m}$ instead of $63 \mu \mathrm{m}$, although a difference in source material could also play a role. There is, however, no significant difference between the $>125 \mu \mathrm{m}$ and total fractions of the poorly preserved sample.

Assessing cleanness is not straightforward, as this is not a strict quantitative feature and many factors may interfere. None the less our method shows that the amount of clean tests increases significantly during the ultrasonic treatment (Fig. 1c). For the well-preserved sample, $>50 \%$ of the foraminifera is clean within only $2 \mathrm{~min}(120 \mathrm{~s})$, while it takes 3 min more $(300 \mathrm{~s})$ for the less well-preserved sample. It is clear that even poorly preserved samples benefit from ultrasound treatment and that, with longer duration, the cleanness of the foraminifera starts resembling those from the better preserved sample. Figure 1d and e show SEM images of well-preserved and poorly preserved specimens after various exposures to ultrasound treatment.

\section{Conclusion}

Assessing the influence of ultrasound on test preservation has been attempted before with contradictory results, probably due to differences in starting material, methods and/or studied size 
a
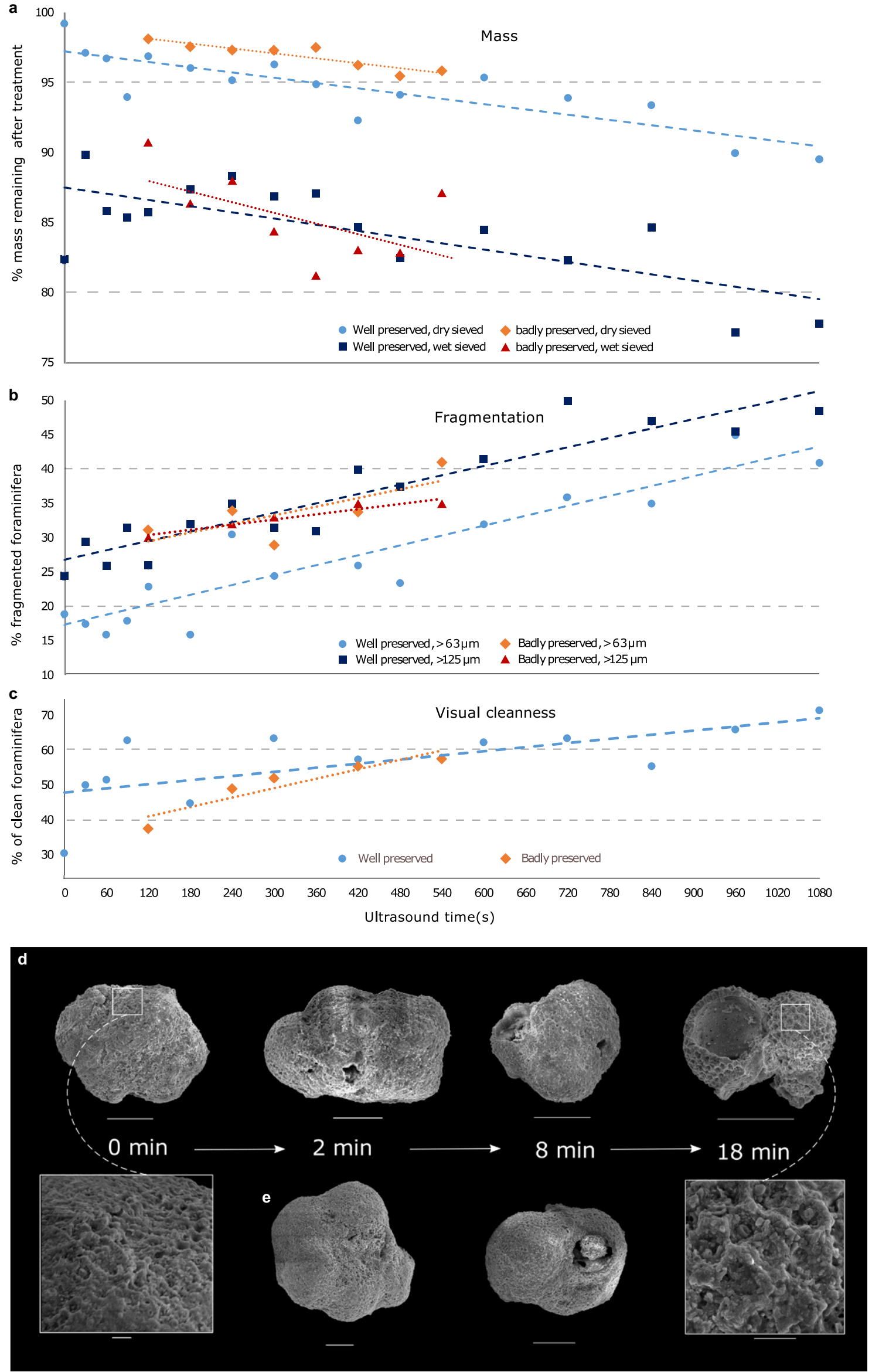

Fig. 1. (a) Mass loss with increasing duration of ultrasonic treatment. (b) Percentage of fragmented planktic foraminifera. (c) Percentage of clean foraminifera. (d) SEM images of planktic foraminifera from the well-preserved sample for 0, 2, 8 and 18 min of ultrasound time. The close-ups show details of the surface texture of the planktic foraminifera at 0 and $18 \mathrm{~min}$. (e) SEM images of planktic foraminifera from the poorly preserved sample for 2 and 8 min of ultrasound time. Scale bars in (d) and (e) delineate 100 and $10 \mu \mathrm{m}$ for the close-ups. 
fraction. Our preservation states after ultrasonic treatment and subsequent wet-sieving are controlled by a trade-off between cleanness and test damage. Longer ultrasound exposure yields generally cleaner foraminifera, which is intended, yet at the cost of a larger number of damaged foraminifera, which should be avoided for assemblage analyses. In our experiment, the optimal duration is $2-5 \mathrm{~min}$, but in order to propose a standard procedure for ultrasound treatment, this should be further tested on a caseby-case basis.

In case ultrasound treatment is needed to improve the quality of a microfossil assemblage, determination of the required duration has to take into account the initial preservation state and the envisaged research goal. Fragile microfossils, such as most planktic foraminifera, require a shorter duration to avoid fragmentation. A study dealing mainly with benthic foraminifera may benefit from longer ultrasound treatment. When microfossils are fully covered with sediment, or when limited lithification is present, longer treatment times could also be advisable. A wide range of possible factors can diminish the initial preservation and, while some of these can be remediated by ultrasonic treatment, this is no catch-all method for easy improvements. A more in-depth study should try to assess more shell parameters on a generic or species level within different lithologies.

Scientific editing by Sigal Abramovich

\section{References}

Hodgkinson, R.L. 1991. Microfossil processing: a damage report. Micropaleontology, 37, 320-326.

Kennedy, A.E. \& Coe, A.L. 2014. Development of the freeze-thaw processing technique for disaggregation of indurated mudrocks and enhanced recovery of calcareous microfossils. Journal of Micropalaeontology, 33, 193-203, http:// doi.org/10.1144/jmpaleo2013-020

Lirer, F. 2000. A new technique for retrieving calcareous microfossils from lithified lime deposits. Micropaleontology, 46, 365-369.

Nguyen, T.M.P., Petrizzo, M.R., Stassen, P. \& Speijer, R.P. 2011. Dissolution susceptibility of Paleocene-Eocene planktic foraminifera: Implications for palaeoceanographic reconstructions. Marine Micropaleontology, 81, 1-21.

Norris, R.D., Wilson, P.A. et al. 2014. Site U1407. In: Norris, R.D., Wilson, P.A., Blum, P. \& Expedition 342 Scientists (eds) Proceedings of the IODP, $\mathbf{3 4 2}$. International Ocean Drilling Program, College Station, TX, 1-106. 